\title{
Clinical trial regulation in Argentina: overview and analysis of regulatory framework, use of existing tools, and researchers' perspectives to identify potential barriers
}

\author{
Lauren White, ${ }^{1}$ Zulma Ortiz, ${ }^{2}$ Luis G. Cuervo, ${ }^{3}$ and Ludovic Reveiz ${ }^{3}$
}

Suggested citation

White L, Ortiz Z, Cuervo LG, Reveiz L. Clinical trial regulation in Argentina: overview and analysis of regulatory framework, use of existing tools, and researchers' perspectives to identify potential barriers. Rev Panam Salud Publica. 2011;30(5):445-52.

ABSTRACT Objective. To review and analyze the regulatory framework of clinical trial registration, use of existing tools (publicly accessible national/international registration databases), and users' perspectives to identify possible barriers to registration compliance by sponsors and researchers in Argentina.

Methods. Internationally registered trials recruiting patients in Argentina were found through clincialtrials.gov and the International Clinical Trial Registration Platform (ICTRP) and compared with publically available clinical trials registered through the National Administration of Drugs, Foods, and Medical Devices (ANMAT). A questionnaire addressing hypothesized attitudinal, knowledge-related, idiomatic, technical, economic, and regulatory barriers that could discourage or impede registration of clinical trials was developed, and semi-structured, in-depth interviews were conducted with a purposively selected sample of researchers (investigators, sponsors, and monitors) in Argentina.

Results. A response rate of $74.3 \%(\mathrm{n}=29)$ was achieved, and 27 interviews were ultimately used for analysis. Results suggested that the high proportion of foreign-sponsored or multinational trials (64.8\% of all protocols approved by ANMAT from 1994-2006) may contribute to a communication gap between locally based investigators and foreign-based administrative officials. A lack of knowledge about available international registration tools and limited awareness of the importance of registration were also identified as limiting factors for local investigators and sponsors.

Conclusions. To increase compliance and promote clinical trial registration in Argentina, national health authorities, sponsors, and local investigators could take the following steps: implement a grassroots educational campaign to improve clinical trial regulation, support local investigator-sponsor-initiated clinical trials, and/or encourage local and regional scientific journal compliance with standards from the International Committee of Medical Journal Editors (ICMJE) and/or the World Association of Medical Editors (WAME).

Key words Clinical trials as topic; registries; publication bias; Argentina.

1 University of Virginia, Charlottesville, Virginia, United States of America. Send correspondence to: Lauren White, law2yd@virginia.edu 2 Research and Training, Instituto de Investigaciónes
Epidemiológicas, Academia Nacional de Medicina,
Buenos Aires, Argentina.
3 Public Policies and Research for Health, Health Systems Based on Primary Health Care (HSS), Pan American Health Organization, Washington, DC, United States of America. 
Clinical trials are an invaluable tool for health care professionals because they provide evidence on the benefits and negative effects of treatments while accounting for possible random variation and bias. The World Health Organization (WHO) defines a clinical trial as "any research study that prospectively assigns human participants or groups of humans to one or more health-related interventions to evaluate the effects on health outcomes" (1). Because the nature of clinical trials implicitly requires the participation of patients, the observance of ethical and moral obligations is critical (2). There is evidence indicating that investigators, sponsors, and scientific journals contribute to bias by selectively submitting or publishing trials with positive or controversial results (3-6). Consequently, clinical trial registration acts to enhance transparency, reduce selective reporting and publication bias, and limit duplication of efforts. For these reasons, WHO considers clinical trial registration to be "a scientific, ethical, and moral responsibility" (1).

Multiple international groups, including WHO, the Ottawa Group, the World Association of Medical Editors (WAME), the World Medical Association (WMA), and the International Committee of Medical Journal Editors (ICMJE), have endorsed registering clinical trials in publically accessible registries before the recruitment of the first patient (1, 7-12). While sponsors are responsible for the registration process, investigators have an obligation to ensure that sponsors are complying with this rule of transparency (7). However, in many cases, registration compliance is low because of minimal legislation, regulation, or enforcement (13). In some countries there are specific requirements for clinical trial registration. For example, in the United States, Section 801 of the Food and Drug Administration (FDA) Amendments Act of 2007 mandates registration of all phase II-IV trials in clinicaltrials.gov, a publically accessible registry (14). If not bound by legislation to a specific registry, sponsors may choose to register with the WHO International Clinical Trials Registration Platform (ICTRP) data- base. This meta-registry consists of 14 "primary registries" (regional and country databases that meet specific ICTRP criteria for content, quality and validity, accessibility, unique identification, technical capacity, and administration, as well as the requirements of the ICMJE) and three "partner registries" (which meet many of the same criteria and must be affiliates of the primary registries or other ICMJE-approved databases, such as clinicaltrials.gov) plus registries working with the ICTRP toward primary registry classification (1).

In the past few decades, clinical trial recruitment has rapidly increased in low- and middle-income countries. The fastest growth rates for clinical trials are now in the developing world (15). Latin America has become an increasingly attractive location for international pharmaceutical companies because of high recruitment rates, scant regulation, and access to "treatment-naïve" populations (those that have never been medically treated) (16). Exponential growth in the number of clinical trials has left Latin American countries scrambling to provide appropriate oversight and regulation and searching for ways to ensure ethical conduct, use, and dissemination of research results. However, the region still needs an easily accessible, ICTRP-compliant primary or regional registry. In 2008, estimates indicated that $30 \%-40 \%$ of clinical trials involved lowor middle-income countries, but only $9.9 \%$ of ICTRP-registered studies belonged to this demographic, suggesting a substantial disparity between the number of trials executed and the number of trials registered (17).

Argentina has been no exception with regard to the phenomenon of clinical trial globalization. By 2008, the country had an average growth rate of $26.9 \%$ in the number of new trials occurring annually (15). It is difficult to determine how many trials remain unregistered, but estimates suggest only $10 \%-20 \%$ of all trials involving humans are currently subject to regulation (18). Nevertheless, Argentina has made some inroads in regulating clinical research. In 1992, the Argentine Ministry of Health founded the National Administration of Drugs, Foods and Medical Devices (Administración Nacional de Medicamentos, Alimentos, y Tecnología Médica, ANMAT). The decentralized agency evaluates prospective protocols and carries out regular inspections of clinical trial sites. Key legislation that affects clinical trial regulation in Argentina includes Disposition 5330/97-guidelines for conducting clinical trials based on the Good Clinical Practice (GCP) protocol published by the International Conference on Harmonisation of Technical Requirements for Registration of Pharmaceuticals for Human Use (ICH)—and Resolution 1490/07, which aimed to further standardize practices regarding participants in clinical trials.

In 2009, Argentina's Ministry of Health outlined plans for a mandatory national registry for clinical trials in human beings in Disposition 102/2009 (19, 20). The more recent Disposition 6677/2010 actualized these plans with the launching of Argentina's Database for Clinical Pharmacology Studies (Base de Consultas acerca de los Estudios en Farmacología Clínica) (21). This site represents a major advancement in improving compliance with national regulation, protecting participant safety, and ultimately encouraging registration with ICTRP-compliant registries.

The purpose of this study was to identify barriers that may exist for researchers in Argentina in the use of existing tools for clinical trial registration based on an analysis of trials currently registered in international, publically accessible databases and a survey examining the perspectives and attitudes of researchers (investigators, sponsors, and monitors) and policy-makers toward clinical trial registration in Argentina.

\section{MATERIALS AND METHODS}

\section{Inventory of currently registered trials}

An analysis of currently registered trials identified through advanced searches via the ICTRP Search Portal (http:// apps.who.int/trialsearch/AdvSearch. aspx) and clinicaltrials.gov (a service of the U.S. National Institutes of Health (NIH)) was completed and the findings compared with publically available clinical trials registered through ANMAT. Clinicaltrials.gov requires and can thus sort clinical trials by the countries of recruitment and type of sponsorship. The ICTRP lists the sponsors but does not categorize them. Therefore, for trials found through the ICTRP Search Portal, the country of primary sponsorship; type of sponsorship (academic, governmental, hospital, industry, or other); registry used for registration; and additional number of recruiting countries were compiled by hand. The summary of trials reflects search results as of 
July 7, 2010. Summaries of worldwide and South American recruitment represent the geographical divisions observed by clinicaltrials.gov (http:/ / clinicaltrials. gov/ct2/search/map).

\section{Survey}

A translated and culturally adapted Spanish-language survey ${ }^{4}$ based on an English-language questionnaire previously administered in 2007 to researchers participating in internationally registered clinical trials was the main instrument for the interview (22). Questions were added to address the following types of hypothesized barriers: attitudinal, knowledge, economic, idiomatic, technical, and regulatory. Three separate forward-translations by native speakers of the target language (Spanish) and three separate back-translations by native English speakers were performed. A checklist was used to compare linguistic and conceptual equivalence. Preference was given to conducting the interviews in person, but when necessary interviews were completed by telephone. The corresponding author conducted interviews in either Spanish or English depending on the preference of the interviewee. Participants were chosen for the survey from a list of contacts provided by the National Academy of Medicine (Academia Nacional de Medicina) Institute of Epidemiological Research (Instituto de Investigaciónes Epidemiológicas) in Buenos Aires and the Health Research Commission (Comisión Nacional Salud Investiga) of Argentina's National Ministry of Health. The inclusion criteria were 1) involvement in clinical investigation, with at least three years of experience, and 2) having carried out, supervised, or completed at least one clinical trial.

\section{RESULTS}

\section{Inventory of currently registered trials}

The number of trials recruiting in Argentina has grown substantially in the past decade. According to data from clinicaltrials.gov, Argentina represents 23.0\% of South America's recruitment sites. In 1999, clinicaltrials.gov had registered only nine trials with recruitment in Argentina, but as of July 7, 2010, the

\footnotetext{
4 Samples available upon request from the corresponding author.
}

TABLE 1. Classification of sponsors for clinical trials recruiting patients in Argentina, according to clinicaltrials.gov, July 2010

\begin{tabular}{lrr}
\hline \multirow{2}{*}{ Sponsor } & \multicolumn{2}{c}{ Clinical trials } \\
\cline { 2 - 3 } & No. & $\%$ \\
\hline Industry & 853 & 84.0 \\
University/organization & 103 & 10.1 \\
U.S. National Institutes of Health (NIH) & 33 & 3.3 \\
Clinical research network & 18 & 1.8 \\
Government (excluding U.S. federal government) & 5 & 0.5 \\
U.S. federal agency (excluding NIH) & 3 & 0.3 \\
Total & 1015 & 100 \\
\hline
\end{tabular}

FIGURE 1. Profile of sponsorship for trials regulated by Argentina's National Administration of Drugs, Foods and Medical Devices (ANMAT), 1994-2006, by organization type ${ }^{a}$

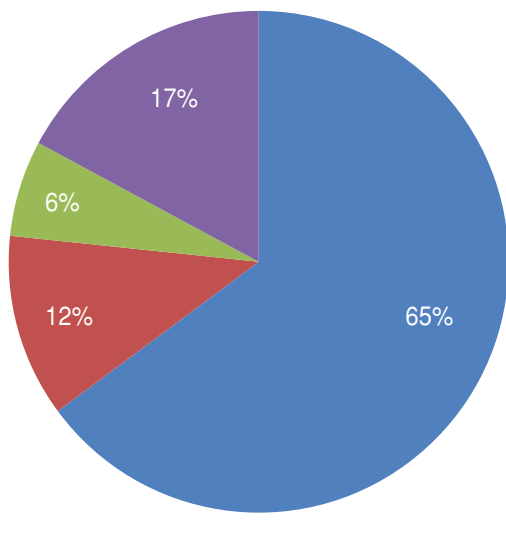

International Pharmaceutical Companies

National Pharmaceutical Companies

Independent Researchers

Contract Research Organization/ Site Management Organization

a Data from: Perez A. Clinical trials in Argentina: 10 years of experience [workshop presentation]. Presented at the 43rd Annual Meeting of Drug Information Association, Atlanta, 17-21 June, 2007.

database showed 1015 trials as currently recruiting or having recruited in Argentina (Table 1). On that same date, ICTRP showed 1054 cumulative clinical trials. Because clinicaltrials.gov is an ICMJE-approved registry, all of the trials registered with clinicaltrials.gov can be found through the ICTRP. This suggests that approximately $96.3 \%$ of all registrations for trials recruiting in Argentina occur through clinicaltrials.gov.

Foreign sponsors have played a key role in this rapid increase. According to clinicaltrials.gov, as of July 2010, national and international industry funded at least $84.0 \%$ of all clinical trials occurring in Argentina (Table 1), while ANMAT records (for 1994-2006) indicated that international pharmaceutical companies alone sponsored at least $64.8 \%$ of all trials (Figure 1). ${ }^{5}$ ICTRP

\footnotetext{
5 Perez A. Clinical trials in Argentina: 10 years of experience [workshop presentation]. Presented at the 43rd Annual Meeting of Drug Information Association, Atlanta, 17-21 June 2007.
}

showed that 254 trials were currently recruiting in Argentina, but only 13 (5.1\%) had sponsors from within the country. Of those 254 trials, sponsors registered 238 trials $(93.7 \%)$ using clinicaltrials.gov. For the remaining 16 trials, the International Standard Randomised Controlled Trial Number (ISRCTN) Registry, Australian New Zealand Clinical Trial Registry, and Sri Lanka Clinical Trials Registry were used as primary registries. Comparison of the number of trials searchable through ICTRP with the number of protocols approved by ANMAT between 1999 and 2006 indicates that sponsors only registered $38.5 \%$ of trials (476 out of 1235 ) with an ICTRPcompliant database during that period (Figure 2).

As of February 1, 2011, there were 831 studies registered through Argentina's new Database for Clinical Pharmacology Studies (21). The database includes fields for the clinical trial's start date, title, phase, sponsor, representative, pri- 
FIGURE 2. Comparison of number of clinical trials in Argentina registered with ANMATa,b versus ICTRPc primary or partner registries from 1999-2006, for study of potential barriers to registration compliance, Buenos Aires City, July 2010

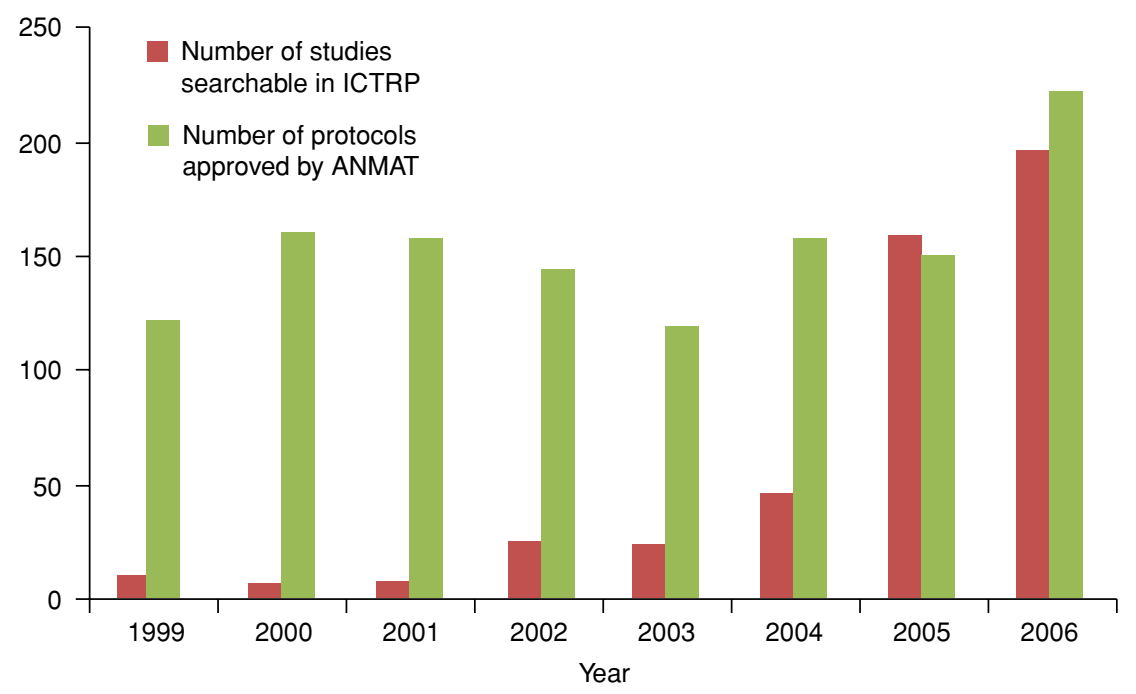

a ANMAT: National Administration of Drugs, Foods and Medical Devices.

b Data from: Perez A. Clinical trials in Argentina: 10 years of experience [workshop presentation]. Presented at the 43rd Annual Meeting of Drug Information Association, Atlanta, 17-21 June 2007.

c ICTRP: International Clinical Trials Registration Platform.

mary investigator, study sites, and current status, and the name of the ethics committee(s) that approved it. Although the fields do not fully match the 20 standard item fields of the WHO database, and the database is not ICTRP-compliant, it is an important first step toward having all clinical trials available in international, publically accessible registries, in accordance with PAHO's Policy on Research for Health (23).

\section{Survey}

This study used data from 27 in-depth, semi-structured interviews conducted with purposively selected national-level researchers in Argentina. A total of 39 individuals were contacted for participation and 29 interviews were conducted, yielding an overall response rate of $74.3 \%$. Two participants were later identified as not fully meeting the inclusion criteria, so their responses were not included in the analysis, resulting in a final population size of 27. Some participants did not answer all of the survey questions. Twenty-one surveys were conducted in-person, three by telephone, and three electronically; 19 participants were investigators or sub-investigators, four were sponsors, and the remaining participants were coordinators, moni- tors, and protocol evaluators. Participants were asked to identify their primary affiliation as academic, industry, hospital, governmental, or other (Table 2). The authors did not further verify these self-classifications.

Among those interviewed, $63.0 \%$ or 17 out of 27 said they had a high or adequate level of knowledge about the recently enacted Resolution 102/2009, and $88.5 \%$ (23 out of 26) said they would be willing to use the Argentine registry once it becomes accessible. Most interviewees $(70.4 \%$ or 19 out of 27$)$ were in direct agreement with the 20 standard item fields required by WHO for registration. Three survey participants (out of a total of 27) supported the addition of more fields to the minimal data set, while five wanted to eliminate some of the required fields. Although $74.0 \%$ (20 out of 27 survey participants) were familiar with clinicaltrials.gov, most had very limited experience or were unfamiliar with other existing international registries such as controlled-trials.com (ISRCTN.org) or latinrec.org (Table 3).

Of the investigators with ongoing trials, $50.0 \%$ (8 out of 16 ) knew the registration status of the trials in which they were currently participating. In total, survey participants were currently managing or overseeing 62 ongoing clinical trials. Based on the questionnaire responses, $37.1 \%$ (23) of the 62 trials were registered in a database accessible to the public, $62.9 \%$ (39) were not registered or had an unknown registration status, and $24.2 \%$ (15) were available in a register that meets WHO ICTRP standards. None of those surveyed were aware of their employer having declined to register a trial or having provided incomplete responses to the required fields for registration. This latter information was based on interviewees' perceptions and thus could not be verified in a systematic manner.

According to the interviewees, language is unlikely to be a significant barrier to trial registration. At least $96.2 \%$ $(25 / 26)$ of those surveyed considered their level of technical English sufficient to search for or register a clinical trial using the existing platforms. None of those surveyed indicated problems using the aforementioned sites due to idiomatic reasons, and $22.2 \%(6 / 27)$ had registered trials in English databases. However, interviewees believed that English language proficiency could be a barrier for Argentine researchers working outside the city of Buenos Aires. The scope of this survey did not allow for analysis of the accuracy of those perceptions.

TABLE 2. Demographic characteristics of survey participants $(n=27)$ in study of potential barriers to clinical trial registration compliance in Argentina, Buenos Aires City, July 2010

\begin{tabular}{lcr}
\hline & \multicolumn{2}{c}{ Survey } \\
& \multicolumn{2}{c}{ participants } \\
\cline { 2 - 3 } Characteristic & No. & $\%$ \\
\hline Age (years) & $46.6 \pm 8.9$ & NA $^{\mathrm{a}}$ \\
Average experience in & & \\
$\quad$ clinical research (years) & $14.6 \pm 8.8$ & $\mathrm{NA}$ \\
Sex & & \\
Male & 15 & 55.6 \\
Female & 12 & 44.4 \\
Role in clinical research & & \\
Investigator & 15 & 55.6 \\
Sub-investigator & 4 & 14.8 \\
Sponsor & 4 & 14.8 \\
Coordinator & 2 & 7.4 \\
Monitor & 1 & 3.7 \\
Protocol evaluator & 1 & 3.7 \\
Primary affiliation & & \\
$\quad$ Academic & 6 & 22.2 \\
Governmental & 3 & 11.1 \\
Hospital & 5 & 18.5 \\
Industry & 8 & 29.6 \\
Other & 5 & 18.5 \\
\hline NA: not applicable & & \\
\hline
\end{tabular}

a NA: not applicable. 
TABLE 3. Experience with clinical trial international registration tools among survey participants in study of potential barriers to registration compliance in Argentina, Buenos Aires City, July 2010

\begin{tabular}{|c|c|c|c|c|c|c|c|}
\hline \multirow[b]{2}{*}{ Frequency } & \multicolumn{2}{|c|}{$\begin{array}{c}\text { Clinicaltrials.gov } \\
\%\end{array}$} & \multicolumn{2}{|c|}{$\begin{array}{c}\text { Controlled-trials.com } \\
\%\end{array}$} & \multicolumn{2}{|c|}{$\begin{array}{c}\text { latinrec.org } \\
\%\end{array}$} & \multirow{2}{*}{$\begin{array}{c}\begin{array}{c}\text { ICTRPa } \\
\%\end{array} \\
\text { Browsing }\end{array}$} \\
\hline & Browsing & Registration & Browsing & Registration & Browsing & Registration & \\
\hline Never or once & 23.1 & 88.5 & 76.9 & 92.3 & 92.3 & 100.0 & 96.2 \\
\hline $2-5$ times & 26.9 & 11.5 & 7.7 & 7.7 & 3.8 & 0.0 & 3.8 \\
\hline More than 5 times & 50.0 & 0.0 & 15.4 & 0.0 & 3.8 & 0.0 & 0.0 \\
\hline
\end{tabular}

a ICTR: International Clinical Trials Registration Platform.

TABLE 4. Survey participant responses $(n=26)$ to the question "Have scientific journals or ethics committees ever required the registration of a clinical trial prior to publication or to gain approval of a protocol?" in study of potential barriers to registration compliance in Argentina, Buenos Aires City, July 2010

\begin{tabular}{|c|c|c|c|c|c|c|}
\hline \multirow[b]{3}{*}{ Entity } & \multicolumn{6}{|c|}{ Response } \\
\hline & \multicolumn{2}{|c|}{ "Yes" or "sometimes" } & \multicolumn{2}{|c|}{ "No" or "do not know" } & \multicolumn{2}{|c|}{ "Does not apply" } \\
\hline & No. & $\%$ & No. & $\%$ & No. & $\%$ \\
\hline Scientific journal & 10 & 38.5 & 14 & 53.8 & 2 & 7.7 \\
\hline Ethics committee & 1 & 3.8 & 18 & 69.2 & 7 & 26.9 \\
\hline
\end{tabular}

Of the 26 study participants who answered the question about publication/ protocol review requirements, only one had been asked by an ethics review committee for proof of clinical trial registration as a requisite for approval whereas scientific journals required proof of registration for every publication for $26.9 \%$ (7 out of 26 participants) and for some publications for $11.5 \%$ (3 out of 26 participants) (Table 4). According to the study participants, the scope and quality of the journal generally determined whether editors sought such a prerequisite: local journals were unlikely to make proof of registration a requirement for publication whereas internationally based journals were likely to do so.

Although computers and Internet access are ubiquitous in the city of Buenos Aires, limited access to both may be a barrier in some parts of the country. About half of those interviewed (14 out of 27) did not think there were any technical barriers for Argentine researchers, while the other half postulated that technical barriers were not a problem for industry but might pose an issue for public research centers with more recent and less comprehensive acquisition of technology. These perceptions were not based on actual performance assessments of registry use at different locations.

\section{DISCUSSION}

Findings from this study suggest that knowledge rather than attitude is the foremost factor impeding registration. Investigators were very unfamiliar with international registration tools other than clinicaltrials.gov. Although many had heard of ICTRP, only a few had used it to search for other clinical trials. Moreover, very few had any knowledge of the registration status of the trials that they were conducting or sponsoring. Because most trials are foreign-sponsored and internationally managed, investigators may feel removed from the process and therefore not responsible for checking the registration status of their trials. Due to this gap between sponsors and researchers, the responsibility for registration sometimes remains in limbo.

However, a very large proportion of those interviewed said they would likely use the Argentine registry once it became available, and a majority agreed with the 20 item fields corresponding to the minimal data set required by WHO. Therefore, stakeholders involved in trial registration should consider using a grassroots educational approach to better inform investigators and sponsors in Argentina about the registration process and requirements. A campaign about the importance of clinical trial registration, particularly the ethical and moral reasons for registering, along with information about current registries and available tools, could help diminish the knowledge barrier, inform sponsors of their obligations, and encourage investigators to act as enforcers.

The clinical trial sponsorship profile in Argentina highlights the difficulties that individual investigator-sponsors face in initiating their own research. Several interviewees indicated an economic barrier in the lack of funding for pre-trial preparations or post-trial conclusions, which suggests that investigators may neglect practices such as protocol development and registration. None of the interviewees indicated having to pay a registration fee, but this is a logical outcome as the majority of interviewees were investigators, who are not responsible for the registration process.

\section{Recommendations}

Although the investigator in Argentina will have to apply to ANMAT for approval, with limited funding and training and no compensation for pretrial activities there is little financial incentive for simultaneous registration in a publically accessible database. Therefore, local researchers should be educated through grassroots initiatives 
about other benefits of registration, such as increased visibility for their research, access to evidence, improved governance of research, opportunities for networking with research groups and individual researchers, and the ability to avoid duplication of efforts. To further build capacity, pre-trial and post-trial proceedings should also be supported. For example, the Comisión Nacional Salud Investiga already offers a research scholarship program that allows investigators to submit protocols for review with the opportunity to receive training on how to better design the study, and eventual funding (following adjustments to the research based on suggested improvements) (24). This approach may be useful in clinical trial research and would support local investigator-sponsors who undertake registration.

The study results indicated two additional entities in the regulatory process that could act as checkpoints for ensuring registration: local or regional scientific journals, and regulatory bodies such as independent ethics committees (IECs) or institutional review boards (IRBs). While both types of regulatory organizations regularly review the protocol of investigations prior to their submission to ANMAT (25), there is no overarching protocol or oversight mechanism governing IECs in Argentina other than the $\mathrm{ICH}$ and its GCP guidelines (26). Submission of the name of the ethics committee that has granted approval to the study is a requirement for registration in the national registry (20). Other countries, such as India, have foregone more formal legislation but have adopted a process of ethics committee approval in which the final stage of review is contingent upon registration $(3,27)$. Likewise, the standard operating procedure advocated by the Pan American Health Organization (PAHO) Ethics Review Committee includes registration with an approved registry prior to ethics committee approval (28).

Local and regional scientific journals could adopt positions similar to those held by the ICMJE and the WAME. In 2005, when the ICMJE first enforced its registration policy, the number of trials submitted to clinicaltrials.gov almost doubled (increasing from 13153 to 22 174) within one month (12). Adopting a similar strategy in Argentina could produce an additional regulatory safety net to capture local trials conducted by research teams that do not aspire to publish their results in the more prestigious journals for which registration is mandatory. Meanwhile, support from local scientific journals will help to contribute to a culture that promotes and fosters clinical trial registration.

To further integrate clinical trial registration into the regulatory environment, international and national registration should be included as a criterion for ANMAT approval. ANMAT could monitor compliance with this requirement at the level of the aforementioned IRBs or IECs or through a separate checkpoint mechanism. Another legislative option would be the adoption of a law requiring registration of all phase III trials with a WHOcompliant (primary or partner) registry or an ICMJE-accepted registry, a measure already implemented in Brazil (29).

\section{Limitations}

This study had several limitations. First, the analysis of clinical trials registered with ANMAT from 1994 to 2006 only considered the number of trials (i.e., the trials were not individually identified), which precluded the opportunity to determine the amount of overlap between trials regulated by ANMAT and those searchable through ICTRP (some trials searchable through ICTRP could be trials not regulated by ANMAT, such as non-pharmacological interventions or educational studies). Second, for the survey portion of the study, the sample size was relatively small, the majority of survey participants (70.4\% or 19 out of 27) were either investigators or sub-investigators, and all but two worked in the city or province of Buenos Aires. Third, many of the survey questions were qualitative, categorical, or open-ended (eliminating the possibility of detailed statistical analysis) and required self-evaluation by the interviewees that could not be confirmed by the authors (e.g., the question about English-language skills). Similarly, the authors could not evaluate all interviewee perceptions, such as those about potential technology or language barriers for researchers outside the city of Buenos Aires.

\section{Conclusion}

Like many countries in Latin America, Argentina has experienced a rapid in- crease in the number of clinical trials recruiting patients within the country over the past decade. Although the country has taken the first step toward supporting clinical trial transparency with the creation of its Database for Clinical Pharmacology Studies, the results of this study indicate that much remains to be done to achieve universal compliance in registration.

Analysis of clinical trials present in the ICTRP database suggests that less than half of the trials regulated by ANMAT are registered in international, publically accessible registries. In addition, researchers interviewed in the survey displayed a lack of knowledge about the importance of registration and the implications of failing to register a clinical trial. While it is important to promote the registration of clinical research (particularly clinical trials) as part of national research policy, the current percentages of internationally registered trials and the responses of the participants in the current study suggest that such measures have not been enough to achieve significant change in Argentina.

To achieve universal compliance, the primary targets of intervention should be individuals and independent institutions. Argentina stands to benefit most by concretizing its developing regulatory and ethics system. Because foreign sponsors manage and register trials abroad, local investigators and sponsors lack knowledge and firsthand experience with the registration process and regulators lack the data that is needed to better inform oversight and monitoring of research within the country. Stakeholders involved in clinical trial registration should seek to promote registration compliance by taking the following steps:

- Building capacity by implementing a knowledge campaign aimed at local investigators and sponsors, and supporting locally initiated and sponsored clinical trial research; and

- Helping local and national scientific journals adopt ICMJE or WAME standards.

Integrating clinical trial registration into the Argentine regulatory environment from the ground up will encourage the solidification of ethical practices in clinical trials, facilitate research gover- 
nance, and promote a culture of transparency embedded in the overarching legislative and regulatory environment of Argentina.

The challenge faced by Argentina is not unique; all countries should strive for clinical trial transparency and more stringent regulation. As this study suggests, achieving universal compliance may require more than the implementa- tion of a national policy. Making sure that local investigators, sponsors, and institutions are aware of the consequences of publication bias and selective reporting will prove critical to advancing the universal goals of evidence-based medicine.

Acknowledgments. The authors thank Iván Insua, Carolina O'Donnell, and the staff of the Comision Nacional Salud Investiga for their contributions to this study; Norka Ruiz Bravo, Michael Rodemeyer, and Jim Turner for their support through the University of Virginia Policy Internship Program; and María Elena Sahores and Josefina Espinoza of the Instituto de Investigaciones Epidemiológicas for their invaluable help in editing the survey and scheduling interviews.

\section{REFERENCES}

1. World Health Organization. International Clinical Trials Registry Platform (ICTRP) [Internet]. Geneva: WHO; c2010. Available from: http://www.who.int/ictrp/en/ Accessed 20 May 2010

2. Krleža-Jerić $K$, Lemmens T. 7th revision of the Declaration of Helsinki: good news for the transparency of clinical trials. Croat Med J. 2009;50(2):105-10.

3. Ghersi D, Pang T. From Mexico to Mali: four years in the history of clinical trial registration. J Evid Based Med. 2009;2(1):1-7.

4. Easterbrook PJ, Gopalan R, Berlin JA, Matthews DR. Publication bias in clinical research. Lancet. 1991;337(8746):867-72.

5. Chan AW, Hróbjartsson A, Haahr M, Gøtzsche PC, Altman DG. Empirical evidence for selective reporting of outcomes in randomized trials: comparison of protocols to published articles. JAMA. 2004;291(20):2457-65.

6. DeMaria AN. Publication bias and journals as policemen. J Am Coll Cardiol. 2004;44(8):1707-8.

7. Krleža-Jerić K, Chan AW, Dickersin K, Sim I, Grimshaw J, Gluud C. Principles for international registration of protocol information and results from human trials of health related interventions: Ottawa statement (part 1). BMJ. 2005;330(7497):956-8.

8. World Association of Medical Editors Editorial Policy Committee. Policy statements [Internet]. WAME; c2010. Available from: http://www.wame.org/resources/policies Accessed 11 June 2010.

9. World Medical Association General Assembly. Declaration of Helsinki-ethical principles for medical research involving human subjects (2008 amendment). Ferney-Voltaire: WMA; 1964. Available from: http://www. wma.net/en/30publications/10policies/b3/ index.html Accessed 20 May 2010.

10. De Angelis CD, Drazen JM, Frizelle FA, Haug C, Hoey J, Horton R, et al. Clinical trial registration: a statement from the International Committee of Medical Journal Editors. New Engl J Med. 2004;351(12):1250-1.

11. De Angelis CD, Drazen JM, Frizelle FA, Haug C, Hoey J, Horton R, et al. Is this clinical trial fully registered? A statement from the International Committee of Medical Journal Editors. New Engl J Med. 2005;352(23):2436-8.

12. Laine $C$, Horton R, De Angelis CD, Drazen JM, Frizelle FA, Godlee F, et al. Clinical trial registration-looking back and moving ahead. N Engl J Med. 2007;356(26):2734-6.

13. Bian ZX, Wu TX. Legislation for trial registration and data transparency. Trials. 2010;11(1): 64.

14. Collier R. Clinical trial registries becoming a reality, but long-term effects remain uncertain. CMAJ. 2009;180(10):1007-8.

15. Thiers FA, Sinskey AJ, Berndt ER. Trends in the globalization of clinical trials. Nat Rev Drug Discov. 2008;7(1):13-4.

16. DeYoung K, Nelson D. Latin America is ripe for trials, and fraud frantic pace could overwhelm controls [Internet]. Washington Post. 2000 Dec 21. Available from: http://www. washingtonpost.com/wp-dyn/content/ article/2008/10/01/AR2008100101182.html Accessed 21 June 2010.

17. Ghersi D, Pang T. En route to international clinical trial transparency. Lancet. 2008;372 (9649):1531-2.

18. Outomuro D. Reflexiones sobre el estado actual de la ética en investigación en Argentina. Acta Bioeth. 2004;10(1):81-94. Available from: http: / / www.scielo.cl/scielo.php?pid=S1726569X2004000100011\&script=sci_arttext Accessed 5 June 2010.

19. Pérez Machín M, Arabetti C. Disposiciones emitidas en la República Argentina para la realización de ensayos clínicos con medicamentos. Rev Cub Salud Pub. 2009;36(2):185-9. Available from: http://scielo.sld.cu/scielo. php?pid=S0864-34662010000200015\&script= sci arttext Accessed 10 October 2010.

20. Comisión Nacional Salud Investiga (AR). Resolución 102/2009 [Internet]. Buenos Aires: Ministerio de Salud. 2009 Feb 2. Available from: http://www.saludinvestiga.org.ar/ marco-regulatorio/disposicion102-2009.asp Accessed 20 May 2010.

21. Administración Nacional de Medicamentos, Alimentos y Tecnología Médica (AR). Base de Consultas acerca de los Estudios en Farmacología Clínica [database on the Internet]. Buenos Aires: ANMAT; 2010. Available from: http://www.anmat.gov.ar/aplicaciones_net/ applications/consultas/ensayos_clinicos/ principal.asp Accessed 1 February 2011.

22. Reveiz L, Krleža-Jerić K, Chan AW, De Aguiar S. Do trialists endorse clinical trial registration? Survey of a Pubmed sample. Trials. 2007;8(1):30.
23. Pan American Health Organization 49th Directing Council. Policy on Research for Health. Washington: PAHO; 2009. Available from: http:/ /new.paho.org/hq/dmdocuments/ 2009/CD49-10-e.pdf Accessed 7 December 2010.

24. Comisión Nacional Salud Investiga (AR). Capacitación en metodología: becas Ramón Carillo-Arturo Oñativia-en curso [Internet]. Buenos Aires: Ministerio de Salud. Available from: http://www.saludinvestiga.org.ar/ becas_en_curso.asp Accessed 1 June 2010.

25. Hurley D, Melgar H, Lipezker M. Regulatory hot topics overview: Canada and Latin America [PowerPoint presentation]. 2008 Sep 16. Available from: www.kendle.com/ uploads/presentations/RAPS_08_Hurley. ppt Accessed 2 June 2010.

26. The EULABOR Project. Descripción de los sistemas de regulación ética nacionales: $\mathrm{Ar}$ gentina [Internet]. 2006 Mar. Available from: http://www.eulabor.org/en/index.html Accessed 28 June 2010.

27. Tharyan P. Ethics committees and clinical trials registration in India: opportunities, obligations, challenges and solutions. Indian J Med Ethics. 2007;4(4):168-9.

28. Pan American Health Organization. Ethics Review Committee Standard Operating Procedures for submitting research proposals. Washington: PAHO; 2009. Available from: http://new.paho.org/hq/dmdocuments/ 2009/074_ENG.pdf Accessed 10 June 2010.

29. WHO International Clinical Trials Registry Platform. Brazil legislates to establish clinical trial registration. Registry Platform e-Note. Jul-Aug 2008. Geneva: World Health Organization; 2008. Available from: http://www. who.int/ictrp/news/WHO_e-Note_no4_JulAug08.pdf Accessed 10 June 2010.

Manuscript received on 4 March 2011. Revised version accepted for publication on 14 June 2011. 
RESUMEN Objetivo. Examinar y analizar el marco normativo del registro de ensayos clínicos, el uso de los instrumentos existentes (bases de datos de registro nacionales o internacionales de acceso público), y las perspectivas de los investigadores para determinar

\section{Reglamentación de ensayos clínicos en la Argentina: panorama y análisis del marco normativo, uso de los instrumentos existentes y perspectivas de los investigadores para identificar posibles obstáculos}

posibles obstáculos al cumplimiento del registro por los patrocinadores y los investigadores en la Argentina.

Métodos. Se realizó una búsqueda en el sitio web clinicaltrials.gov y en la Plataforma Internacional de Registro de Ensayos Clínicos (ICTRP) de los ensayos clínicos registrados en el ámbito internacional que reclutan pacientes en la Argentina y los resultados se compararon con los ensayos clínicos incluidos en el registro de acceso público de la Administración Nacional de Medicamentos, Alimentos y Tecnología Médica (ANMAT). Se elaboró un cuestionario que abordaba los hipotéticos obstáculos relacionados con la actitud hacia el registro y el conocimiento de este, así como obstáculos idiomáticos, técnicos y económicos que podrían desalentar o dificultar el registro de los ensayos clínicos, y se llevaron a cabo entrevistas semiestructuradas exhaustivas en una muestra de investigadores seleccionada para este fin (investigadores clínicos, patrocinadores y monitores) en la Argentina.

Resultados. Se obtuvo una tasa de respuesta de 74,3\% $(n=29)$ y finalmente se analizaron 27 entrevistas. Los resultados sugieren que la proporción elevada de ensayos clínicos con patrocinadores extranjeros o los ensayos multinacionales $(64,8 \%$ de los protocolos aprobados por la ANMAT entre 1994 y el 2006) pueden contribuir a una deficiencia de comunicación entre los investigadores locales y los funcionarios administrativos ubicados en el extranjero. También se identificaron como factores limitantes para los investigadores y los patrocinadores locales la falta de conocimiento de los recursos internacionales disponibles para el registro y el escaso reconocimiento de la importancia del registro.

Conclusiones. Para aumentar el cumplimiento y promover el registro de los ensayos clínicos en la Argentina, las autoridades sanitarias nacionales, los patrocinadores y los investigadores locales podrían adoptar las siguientes medidas: ejecutar una campaña educativa para mejorar la reglamentación de los ensayos clínicos, apoyar los ensayos clínicos iniciados por investigadores o patrocinadores locales, y promover el cumplimiento de las normas del Comité Internacional de Editores de Revistas Médicas (ICMJE) o la Asociación Mundial de Editores Médicos (WAME) por parte de las revistas científicas locales y regionales.

Palabras clave Ensayos clínicos como asunto; sistemas de registros; sesgo de publicación; Argentina. 